\title{
An Farben, Formen und Klängen erfreuen
}

? Herr Dr. Hubatsch, am 1. September haben Sie Ihre neue Hautarztpraxis in Neu-Isenburg eröffnet. Wie fühlen Sie sich?

Hubatsch: Positiv angespannt! Ich freue mich sehr darüber, mein eigener Chef sein $\mathrm{zu}$ dürfen und frei entscheiden $\mathrm{zu}$ können. Schon beim morgendlichen Betreten des Gebäudes kommt eine innere Freude auf, die mich anspornt, das Beste zu geben.

\section{? Warum haben Sie sich für Neu-Isenburg} entschieden?

Hubatsch: Ich bin in Dreieich groß geworden, verbringe viel Zeit in Frankfurt, genau dazwischen liegt Neu-Isenburg. Es ist aus allen Richtungen hervorragend erreichbar, liegt weder zu zentral noch zu abgeschieden und die im Umkreis lebenden Menschen sind aufgeschlossen und sehr heterogen bezüglich ihres Alters, Berufs und Herkunft.

\section{? Was sind die Schwerpunkte in Ihrer neuen} Praxis?

Hubatsch: Fünf Säulen bilden das Grundgerüst unserer Praxisklinik: Die klassische Dermatologie, die Lasermedizin, die Dermatochirurgie, die ästhetische Medizin und die Kosmetik.

? Wie lange und warum arbeiten Sie mit den Lumenis-Systemen?

Hubatsch: Die ersten beiden Anschaffungen von Lumenis waren der M22 und der LightSheer Infinity 2014. Ein Jahr später kam der UltraPulse hinzu. Ich bin Per- fektionist. Man kann im Leben nicht alles kaufen, aber bei dem was man kauft, sollte es das Beste sein. Lumenis ist ausgereift, seit Jahrzehnten Marktführer in der dermatologischen Laserbranche und somit der Goldstandard. Gerade beim $\mathrm{CO}_{2}$-Laser gibt es nur einen Laser, der namentlich in den Leitlinien zur Behandlung von Narben genannt wird, und das nicht ohne Grund.

? Was war für Sie der Beweggrund, Dermatologe zu werden?

Hubatsch: Die Dermatologie ist das vielseitigste aller Fachgebiete. Innere Medizin, Pharmakologie, Chirurgie, Rheumatologie, Ästhetik, Psychatrie usw. vereinen sich in unserem Fach. Man kann sich spezialisieren, aber ohne gute Grundlagen in den genannten Fachgebieten und übergeordnetem Denken wird man nie ein guter Dermatologe sein können. Genau diese Herausforderung macht unser Fach so besonders.

? Wie werden Sie neue Patienten gewinnen? Hubatsch: Ganz klar: Qualität. Nichts ist so wertvoll wie ein zufriedener Patient. Die persönliche Weiterempfehlung hat mir über viele Jahre einen großen Patientenstamm gebracht, auf dessen Grundlage ich aufbauen kann. Hinzu kommen soziale Medien wie Facebook, Interviews und Annoncen in regionalen Zeitungen, die monatlichen Afterwork-Veranstaltungen in der Praxis sowie eine selbst geschriebene Homepage.

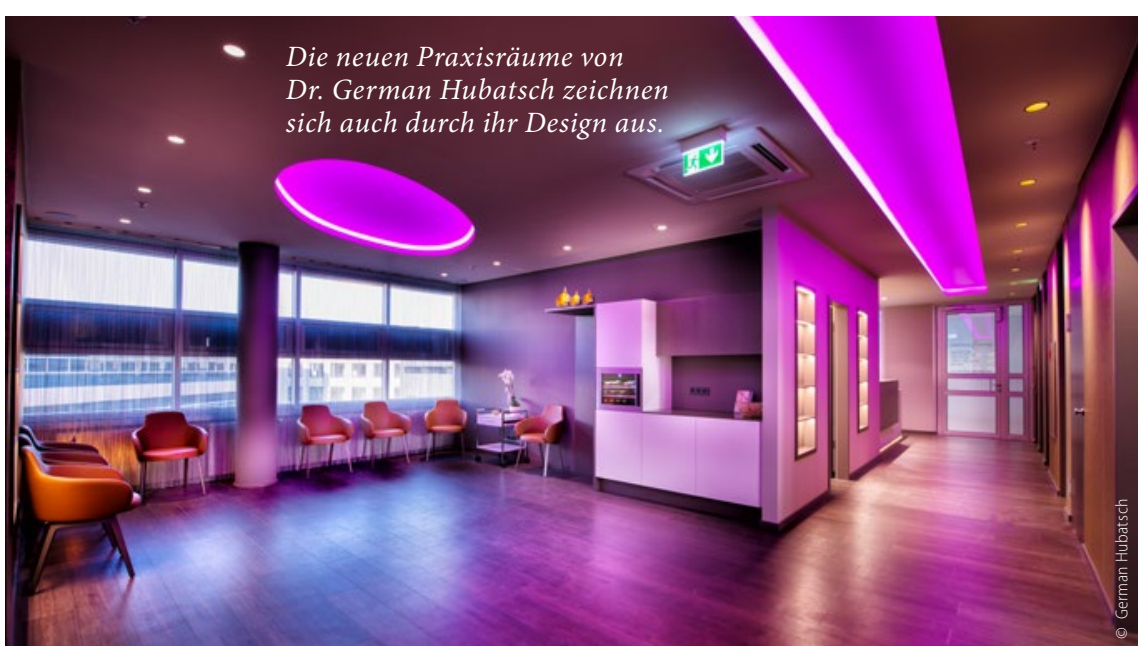

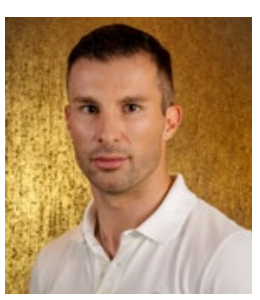

Dr. German

Hubatsch

\section{Martin-Behaim-Straße 4 \\ 63263 Neu-Isenburg \\ www.german-aesthetics.de}

? Gibt es denn für Sie auch noch Freizeit? Hubatsch: Müßiggang im Sinne von Nichtstun seit Jahren sehr wenig. Ich liebe es zu lernen, und deshalb habe ich seit Jahren sehr viel Freizeit auf Fortbildungen, Hospitationen oder mit dem Studium von Fachliteratur verbracht. Ich hoffe, bald wieder mehr Zeit für meinen geliebten Sport zu finden, aber oberste Priorität hat aktuell das Unternehmen Praxis.

? Was raten Sie Ihren Kollegen, die auch eine Praxis eröffnen möchten?

Hubatsch: Ich habe in zwei großen Praxen als Weiterbildungsassistent gearbeitet, zusätzlich die Grundlagen in der Chirurgie und ärztlichem Notdienst gelegt. Ich wusste also genau, worauf es ankommt und habe mir in Eigeninitiative ein sehr breites Spektrum an Medizin angeeignet. Die Unabhängigkeit von nur einer spezifischen Klientel, die Fähigkeit, auch abseits der Dermatologie kompetent zu sein, sind die Grundlagen des Erfolges.

? Wieso haben Sie sich für so ein außergewöhnliches Design entschieden?

Hubatsch: Ein Drittel der Lebenszeit schläft man, von den anderen zwei Dritteln verbringt man wiederum zwei Drittel auf der Arbeit. Ich muss nicht zwei Wochen im Jahr auf die Malediven fliegen, wenn ich mich 50 Wochen in meiner Praxis wohlfühle. Dort wäre ich isoliert, hier kann ich die Freude an schönen Dingen mit meinen Patienten und Freunden teilen. Selbst wenn man krank ist, soll man sich bei Betreten der Praxis nicht krank fühlen. Die Zeit ist so begrenzt auf dieser Welt - warum sollte man sich nicht an Farben, Formen und Klängen tagtäglich erfreuen?!

Das Interview führte Jens Schramm.

Nach Informationen von Lumenis 